\title{
Video EEG Monitorizasyon Ünitesinde Takip Edilen Epilepsi Hastalarının Retrospektif EKG Kayıtlarının Aritmi Açısından İncelenmesi
}

\author{
Pinar UZUN USLU ${ }^{1}$, Aylin BİCAN DEMIR ${ }^{2}$, İbrahim BORA ${ }^{2}$ \\ 1 Eskişehir Şehir Hastanesi, Nöroloji Kliniği, Eskişehir. \\ 2 Bursa Uludağ Üniversitesi Tıp Fakültesi, Nöroloji Anabilim Dalı, Bursa.
}

ÖZET

Video EEG monitorizasyon (VEM) ünitelerinde hastalara iki elektrot aracı̆̆ıyla eș zamanlı EKG monitörizasyonu yapılmaktadır. EKG kaydının olması, EEG artefaktlarının epileptik deşarjlardan ayırımının yanı sıra, interiktal ya da periiktal dönemde ortaya çıkabilicek kardiyak aritmileri de gösterebilmektedir. Bu aritmilerin ayrıca ani beklenmeyen ölümlere (SUDEP: Sudden unexpexcted death of epilepsy) yol açabileceği düşünülmektedir. Bu çalışmada VEM ünitelerinde takip edilen hastaların eş zamanlı EEG-EKG kayıtları retrospektif değerlendirilerek aritmilerin tanımlanması ve ilişkili olabilecek faktörlerin belirlenmesi araştırılması amaçlandı. Mart 2014 ile Şubat 2016 arasında VEM ünitesinde takip edilen hastaların EEG-EKG kayıtları ve nöbet semiyolojileri retrospektif olarak incelendi. Yaş, cinsiyet, nöbet sınıflandırması, nöbet sayısı, aritmi varlığı, ortaya çıkış zamanı ve tiplendirmesi yapılarak, bunların birbiri ile ilişkisi değerlendirildi. Çalışmaya dahil edilen 165 hastanın \%45,4'ü (n:75) kadın, \%54,5’i (n:90) erkekti. Kadın hastaların yas ortalaması 34 \pm 3 iken erkeklarin yas ortalaması $49 \pm 5$ idi. Tüm bu hastaların EEG- EKG ve nöbet bulguları değerlendirildi. Hastaların \%77’si (n:127) fokal, \%23'ü (n:38) jeneralize epilepsi hastasıydı. Kayıt edilen toplam 370 fokal nöbetin \%62,9’u (n:233) temporal, \%24,8’i (n:92) frontal, \%9 (n:35) parietoksipital kaynakliydı. Temporal lob kaynaklı nöbetlerin \%35'inde (n:82), frontal lob nöbetlerin \%50’sinde (n:46) parietoksipital nöbetlerin \%11'inde (n:4) iktal taşikardi saptandı. Tespit edilen 79 jeneralize nöbetin \%87'sinde (n:69) iktal taşikardi tespit edildi. Temporal lob kaynaklı nöbetlerin \%5,6'sında (n: 13), frontal nöbetlerin \%2,2'sinde (n:2) ve primer jeneralize nöbetlerin ise \%1'inde (n:8) iktal bradikardi saptandı. Temporal epilepsili $1(\% 0,43)$ hastada ise iktal asistoli tespit edildi. Çalışmamızda epilepside ortaya çıkabilecek ritm bozukluklarının sıklık, nöbet semiyolojisi ve EEG ile ilişkisinin belirlenmesi amaçlanmıştır.

Anahtar Kelimeler: İktal EKG. İktal taşikardi. SUDEP. İktal bradikardi.

Evaluation of the Simultaneous EEG-ECG Recordings of the Patients in Video EEG Monitorization Units in Regard to the Arrhythmias.

\begin{abstract}
Video EEG monitoring (VEM) units are used for simultaneous ECG monitoring with two electrodes. The presence of ECG recordings may also indicate cardiac arrhythmias, which may ocur in the interictal or periictal period, as well as the differentiation of EEG artifacts from epileptic discharges. These arrhythmias are also thought to lead to sudden unexpected deaths (SUDEP: sudden epilepsy death). The aim of this study was to evaluate the simultaneous EEG-ECG recordings of the patients who were followed in VEM units and to determine the factors that may be related to the identification of the arrhythmias. EEG-ECG recordings and seizure semiology of the patients who were followed in VEM unit between March 2014 and February 2016 were retrospectively analyzed. Age, gender, seizure classification, seizure number, presence of arrhythmia, type of arrhythmia and their relation with each other were evaluated. Of the 165 patients included in the study, $45.4 \%$ (n: 75 ) were female and $54.5 \%$ (n: 90) were male. The mean age of the females was $34 \pm 3$ years and the mean age of the males was $49 \pm 5$ years. EEG-ECG and seizure findings of all these patients were evaluated. $77 \%$ (n: 127$)$ of the patients were focal and $23 \%$ (n: 38) were generalized epilepsy patients. Of the total recorded 370 focal seizures, $62,9 \%$ (n:233) were temporal, 24,8\% (n:92) were frontal, 9\% (n:35) were from parieto occipital origin. Ictal tachycardia was found in 35\% (n:82) of the temporal lobe-induced seizures, $50 \%$ (n:46) of the frontal lobe seizures and 11\% (n:4) of the parieto-occipital seizures. Ictal tachycardia was detected in 87\% (n:69) of 79 generalized seizures. In $5.6 \%$ (n:13) of the temporal lobe-induced seizures , 2.2\% (n: 2) of frontal seizures and $1 \%$ (n: 8) of primary generalized seizures were ictal bradycardia. In patients with temporal epilepsy was detected ictal asystole $0.43 \%$ (n:1). The aim of this study was to determine frequency of rhythm disorders that may occur in epilepsy, the relationship between seizure semiology and EEG.
\end{abstract}

Key Words: Ictal ECG. Ictal tachycardia. SUDEP. Ictal bradycardia.

Geliş Tarihi: 07 Ekim 2018

Kabul Tarihi: 08 Ocak 2019

* 32.Ulusal Nörofizyoloji EEG-EMG Kongresi'nde (27 Nisan- 1 Mayıs 2016, Bodrum) Sözel Bildiri olarak sunulmuştur.
Dr. Pınar UZUN USLU

Eskişehir Şehir Hastanesi,

Nöroloji Kliniği,

Eskişehir

Tel.: 02222374800

E-posta: drpinaruzun@gmail.com 
Uzun süreli Video EEG monitorizasyon (VEM) üniteleri non-epileptik nöbetleri ortaya çıkarma, epileptik nöbetleri ve eş zamanlı EEG'leri ile inceleyerek epilepsi nöbetlerini sınıflandırma, cerrahi adayı epilepsi hastalarının ise nöbet başlangıç alanını saptama imkanlarını sunmaktadır. ${ }^{1}$ VEM ünitelerinde hastalara ayrıca hastalara rutin olarak iki elektrot aracığıyla eş zamanlı EKG monitörizasyonu yapılmaktadır. EKG kaydının olması, EEG artefaktlarının epileptik deşarjlardan ayırımının yanı sıra, bu hastaların interiktal ya da periiktal dönemde ortaya çıkabilecek kardiyak aritmilerini de gösterebilmektedir. ${ }^{2}$ Nöbet sırasında kalp ritmindeki değişiklikler sık görülür. Aritmiye yol açan mekanizma epileptik nöbetlerde otonomik disfonksiyonun ortaya çıkmasıdır. Bu disfonksiyon parasempatik ve sempatik sistemler arası dengenin bozulması ile ortaya çıkar. Özellikle anterior singulat, insular, posterior orbito-frontal ve ön frontal korteksler, amigdala ve hipotalamus ile birlikte otonomik sinir sistemini etkilemede anahtar rol oynar. Epileptik nöbetlerde bu yapılarda ortaya çıkan veya bu yapılara yayılan iktal deşarjlar sempatik çıkışların artmasına yol açabilir. Sinüs taşikardisi gibi sempatik yanıtlar, en sık görülen değişikliklerdir. Bradikardi, asistoli gibi parasempatik yanıtlar da iktal deşarjların depresyon yanıtlarını yöneten kortikal bölgelere yayılması ile ortaya çıkabilir. Çeşitli nöral yapıların deneysel uyarımını içeren araştırmalar, epileptik deşarjların sağ insular kortekse yayılmasının, kalp atış hızını etkileyen sempatik-parasempatik değişikliklerin birincil nedeni olduğunu ortaya koymaktadır., ${ }^{3,4} \mathrm{Bu}$ otonomik disregülasyonun kardiyovasküler sistemin katekolamin reseptörleri üzerinden yol açtığ 1 düşülmekle birlikte son zamanlarda kalp ve beyinde ortak olan iyon kanal mutasyonlarının da üzerinde çalışılmaktadır. Epilepsi ve kardiyak artimiler ilişkisinde tanımlanan mutasyonlardan ilki sodyum kanal geni SCN5A'dır. ${ }^{5}$ Mortalitesi yüksek bir epileptik sendrom olan Dravet Sendromunda SCN1A gen mutasyonu olup bu gene ait mutasyonu olan farelerde SUDEP öncesi bradikardi oluştuğu saptanmıştır. ${ }^{6-8}$ İktal aritmiler arasında bradikardi ve asistoli daha az sıklıkla görülmekle birlikte daha ciddi sonuçlara yola açabilmektedir. Son zamanlarda fokal epileptik nöbetleri olan hastalarda açıklanamayan atonik düşme atakları olması halinde iktal bradikardi ve asistolinin akla gelmesi gerektiği vurgulanmaktadır. Böyle hastalarda uzun süreli EEG ve EKG monitorizasyonu yapmak gerekmektedir. Özellikle iktal asistolinin SUDEP nedeni ile olabileceği bu nedenle böyle hastalarda pace-maker implantasyonun SUDEP riskini azaltabileceği düşünülmektedir. ${ }^{9}$

\section{Gereç ve Yöntem}

Mart 2014 ve Şubat 2016 tarihleri arasında VEM'de takip edilen antiepileptik tedavi almayan ya da antiepi- leptik tedavileri yatış öncesi kesilmiş olan hastaların EEG- EKG ve nöbet semiyolojisini içeren görüntü kayıtları ünitenin mevcut data sisteminden retrospektif incelendi. Psikojen nöbet saptanan hastalar çalışmaya alınmadı. Hastaların yaş, cinsiyet, nöbet sınıflandırması, nöbet sayısı, aritmi varlığı, ortaya çıkış zamanı ve tiplendirmesi yapılarak, bunların birbiri ile ilişkisi değerlendirildi. Epilepsi sınıflaması Uluslararası Epilepsi ile Savaş Derneği (ILAE) rehberine göre yapılmış iken ritm bozuklukları Amerikan Kardiyoloji Koleji/ Amerikan Kalp Cemiyeti/ Avrupa Kardiyoloji Derneği (ACC/AHA/ESC) ortak kılavuzuna göre kategorize edilmiştir. $\mathrm{Bu}$ doğrultuda göre nöbetler fokal başlançlı, jeneralize başlangıçlı ve bilinmeyen olarak üç ana gruba ayrılmıştır. Taşikardi 100atım/dk nın üzerinde, bradikardisi ise $60 \mathrm{atım} / \mathrm{dk}$ altında olan kalp hızları olarak gruplandırılmıştır. Asistoli ise EKG de herhangi bir elektriksel aktivitenin görülmemesidir.

\section{Bulgular}

Çalışmaya toplam 165 hasta dahil edildi. Hastaların \%45,4'ü (n:75) kadın, \%54,5’i (n:90) erkekti. Kadın hastaların yaş ortalaması $34 \pm 3$ iken erkeklarin yaş ortalaması $49 \pm 5$ idi (Tablo I). Çalışmaya alınan hastaların VEM ünitesi data sisteminden retrospektif olarak interiktal-iktal EEG, EKG ve nöbet bulguları değerlendirildi. Nöbet semiyolojileri ve EEG leri birlikte değerlendirildiğinde hastaların \%77'si (n: 127) fokal ve sekonder jeneralize epilepsi iken \%23'ü (n:38) primer jeneralize epilepsiydi (Tablo I). Kayıt edilen toplam 370 fokal nöbetin \%62,9'unda (n: 233) temporal, \%24,8'inde (n:92) frontal, \%9'unda (n:35) parietoksipitalde epileptik odak görüldü (Tablo II). Nöbet semiyolojisi ve EEG si temporal lob kaynaklı olan nöbetlerin \%35'inde (n:82), frontal lob nöbetlerin \%50'sinde (n:46), parietoksipital nöbetlerin \%11'inde (n:4). iktal taşikardi saptandı. Tespit edilen 79 jeneralize nöbetin \%87'sinde (n:69) iktal taşikardi tespit edildi. Temporal lob kaynaklı nöbetlerin \%5,6'sinda (n: 13), frontal nöbetler-in \%2,2'sinde (n:2) ve primer jeneralize nöbetlerin ise \%1'inde (n:8) iktal bradikardi saptand. Temporal lob epilepsili \%0,43 (n:1) hastada ise iktal asistoli saptandı (Tablo III). Saptanan bu asistoli 13 saniye olup spontan olarak sinüs bazal ritmine döndü.

Tablo I. Hastaların demografik özellikleri ve nöbet tipleri

\begin{tabular}{|l|l|l|}
\hline Kadın (dağılım, yaş) & $\% 45,4$ (n:75) & $34 \pm 3$ \\
\hline Erkek (dağıım, yaş) & $\% 54,5$ (n:90) & $49 \pm 5$ \\
\hline & $\begin{array}{l}\text { Fokal ve sekonder } \\
\text { jeneralize }\end{array}$ & Primer jeneralize \\
\hline Epilepsi türleri & $\% 77$ (n: 127) & $\% 23$ (n:38) \\
\hline
\end{tabular}


Tablo II. Fokal nöbetli hastalarda iktal EEG lerde nöbet odağ 1

\begin{tabular}{|l|l|}
\hline Temporal ,(sağ/sol/bitemporal) & $233(\% 62,9),(109 / 103 / 21)$ \\
\hline Frontal , (sağ/sol/ bifrontal) & $92(\% 24,8),(34 / 48 / 10)$ \\
\hline Parietooksipital & $35(\% 9)$ \\
\hline
\end{tabular}

Tablo II. Ritm bozukluğunun nöbet tipine göre dağ1limı

\begin{tabular}{|l|c|c|c|c|}
\hline $\begin{array}{c}\text { Ritm } \\
\text { Bozukluğu }\end{array}$ & Temporal & Frontal & $\begin{array}{c}\text { Primer } \\
\text { Jeneralize }\end{array}$ & $\begin{array}{c}\text { Tüm nöbetler } \\
\text { tiplerinde }\end{array}$ \\
\hline İktal Taşikardi & $82(\% 35)$ & $46(\% 50)$ & $69(\% 87,3)$ & $201(\% 44,8)$ \\
\hline $\begin{array}{l}\text { Iktal } \\
\text { bradikardi }\end{array}$ & $13(\% 5,6)$ & $2(\% 2,2)$ & $8(\% 1)$ & $23(\% 5)$ \\
\hline İktal asistoli & $1(\% 0,43)$ & - & - & $1(\% 0,2)$ \\
\hline
\end{tabular}

\section{Tartışma ve Sonuç}

Sinüs taşikardisi epilepsi nöbetlerinde en s1k görülen ritm bozukluğu olup nöbetlerin \%80'inde görülebilir. ${ }^{10}$ Parsiyel epilepsili hastalarda iktal taşikardi Garcia ve arkadaşları tarafindan \%32 oranınında saptanmıştır. ${ }^{11}$ Refrakter nöbetlerin olduğu temporal lob epilepsilerinde ise Zijlmans ve arkadaşları iktal taşikardi sıklığını \%73, Moseley ve arkadaşları ise \%57 olarak saptanmış iken Di Gennaro ve arkadaşları tarafindan iktal taşikardi temporal lob epilepsilerinde \%92 oranında saptanmıştır. ${ }^{12-14}$ Walker ve fish parsiyel epilepsilerde $\% 64$, jeneralize epilepsilerde $\% 89$, Opherk ve ark. ise parsiyel epilepsilerde $\% 73$, jeneralize epilepsilerde \%100 iktal taşikardi saptanmışlardır. Bizim çalışmamızda ise ilaç tedavisi altında olmayan tüm epilepsiler değerlendirildiğinde iktal taşikardi temporal lob epilepsilerinde $\% 35$, frontal lob epilepsilerinde $\% 50$, primer jeneralize epilepsilerde $\% 87$ oranında saptandı. İktal taşikardi tüm nöbetlerinde en sık görülen aritmi olmakla birlikte tüm literatür gözden geçirildiğinde temporal lob epilepsilerinde ekstratemporal lob epilepsilerine oranla iktal taşikardinin daha sı olduğu ve patofizyolojisinin temporal lobtan kaynaklanabileceği düşünülmektedir. ${ }^{15}$ Çalışmamızda jeneralize epilepsilerdeki iktal taşikardinin daha fazla olmasından hızlı jeneralize olan nöbetler ve noninvaziv EEG nin kısitllılıkları sorumlu tutulabilir. Saçlı deriden çekilen EEG korteksin derin bölgelerinden kaynaklanan nöbet odağını göstermeyebilir. Bunun yanında özellikle hızlı jeneralize olan nöbetlerde kas artefaktı nedeni ile epileptik odak görülemeyebilir. Subdural elektrot aracılığıyla korteksde daha fazla alan doğrudan monitorize edilebilir ayrıca saçlı deriden kaynaklanan artefaktlar minumuma iner. Böylece epileptojenik odak açısından çalışmaların sensitivite ve spesifitesi artırılabilir. İktal taşikardi genellikle asemptomatik seyrederken iktal bradikardi ve iktal asistoli senkop ve hatta SUDEP nedeni olabilir. İktal bradikardi epilepsi hastalarında $\% 6$ oranında görülmekte olup özellikle temporal bölge ile ilişkilendirilmektedir. $^{16,17}$

İktal asistoli ise çok daha nadir görülen bir ritm bozukluğu olup $\% 0,1-\% 0,4$ oranında görülmektedir. ${ }^{18}$ İktal asistolinin de daha çok parsiyel nöbetlerde ve özellikle de temporal lob epilepsilerinde görüldüğü saptanmıştır. ${ }^{19}$ Çalışmamızda iktal bradikardi ve iktal asistoli sıklık ve lokalizasyonu literatür ile uyumludur. Mosely ve ark. İktal asistoli saptanan hastalarda kardiyak pacemaker ile düşme ataklarının azalabileceğini, Duplyakov ve ark. ise iktal asistoli saptanan hastada fiziksel yaralanma ve ani ölümlerin de azabileceğini öne sürmüşlerdir. ${ }^{19,20} \mathrm{Bu}$ nedenle epilepsi nedeni ile takipli hastalarda geçirilen nöbetlerden faklı düşme ya da senkop atakları tanımlanıyorsa uzun süreli kardiyak monitörizasyon planlanmalıdır. Böyle hastalarda epilepsi tedavisinin yönetimi ile birlikte iktal ritm bozukluğunu belirleyebilmek, kardiyak yan etki profili açısından doğru antiepileptiği seçmek ve pace maker endikasyonu koyabilmek SUDEP riskini azaltmada önemli rol oynamaktadır.

\section{Kaynaklar}

1. Stefan H, Hopfengärtner R. Epilepsy monitoring for therapy: challenges and perspectives. Clin Neurophysiol 2009;120 (4):653-8.

2. Rugg-Gunn FJ, Simister RJ, Squirrell M, Holdright DR, Duncan JS. Cardiac arrhythmias in focal epilepsy: a prospective longterm study. Lancet 2004;364(9452):2212-9.

3. Jansen K, Lagae L. Cardiac changes in epilepsy. Seizure: J Brit Epilepsy Assoc 2010;19:455-60. http://dx.doi.org/10.1016/j.seizure.2010.07.008. pii:S10591311(10)00157-3.

4. Oppenheimer SM, Gelb A, Girvin JP, Hachinski VC. Cardiovascular effects of human insular cortex stimulation. Neurology 1992;42:1727-32.

5. Hartmann HA, Colom LV, Sutherland ML, Noebels JL. Selective localization of cardiac SCN5A sodium channels in limbic regions of rat brain. Nat Neurosci 1999;2(7):593-5.

6. Shmuely S, Sisodiya SM, Gunning WB, Sander JW, Thijs RD. Mortality in Dravet syndrome: a review. Epilepsy Behav. 2016;64:69-74.

7. Auerbach DS, Jones J, Clawson BC, Offord J, Lenk GM, Ogiwara I, et al. Altered cardiac electrophysiology and SUDEP in a model of Dravet syndrome. PLoS One 2013;8(10):e77843.

8. Kalume F, Westenbroek RE, Cheah CS, Yu FH, Oakley JC, Scheuer T, et al. Sudden unexpected death in a mouse model of Dravet syndrome. J Clin Invest 2013;123(4):1798-808.

9. Roisin Bartlam, Rajiv Mohanraj. Ictal bradyarrhythmias and asystole requiring pacemaker implantation: Combined EEGECG analysis of 5 cases. Epilepsy \& Behavior 64 (2016) 212215.

10. Sevcencu C, Struijk JJ. Autonomic alterations and cardiac changes in epilepsy. Epilepsia 2010;51:725-37.

11. Garcia M, D'Giano C, Estelles S, Leiguarda R, Rabinowicz A. Ictal tachycardia: its discriminating potential between temporal and extratemporal seizure foci. Seizure 2001;10:415-9.

12. Di Gennaro G, Quarato PP, Sebastiano F, Esposito V, Onorati P, Grammaldo LG, et al. Ictal heart rate increase precedes EEG 


\section{P.U. Uslu, ark.}

discharge in drug-resistant mesial temporal lobe seizures. Clin Neurophysiol 2004;115:1169-77.

13. Zijlmans M, Flanagan D, Gotman J. Heart rate changes and ECG abnormalities during epileptic seizures: prevalence and definition of an objective clinical sign. Epilepsia 2002;43:84754.

14. Moseley BD, Wirrell EC, Nickels K, Johnson JN, Ackerman MJ, Britton J. Electrocardiographic and oximetric changes during partial complex and generalized seizures. Epilepsy Res 2011;95:237-45.

15. Katherine S. Eggleston, Bryan D. Olin , Robert S. Fisher. Ictal tachycardia: The head-heart connection. Seizure 23 (2014) 496-505.

16. Smith PE, Howell SJ, Owen L, Blumhardt LD. Profiles of instant heart rate during partial seizures. Electroencephalogr Clin Neurophysiol 1989;72:207-17.
17. Nei M, Ho RT, Sperling MR. EKG abnormalities during partial seizures in refractory epilepsy. Epilepsia 2000;41:542-8.

18. Devinsky O. Sudden, unexpected death in epilepsy. $N$ Engl $J$ Med 2011; 365: 1801-1811.

19. Lanz M, Oehl B, Brandt A, Schulze-Bonhage A. Seizure induced cardiac asystole in epilepsy patients undergoing long term video-EEG monitoring. Seizure 2011; 20: 167-172.

20. Moseley BD, Ghearing GR, Munger TM, Britton JW. The treatment of ictal asystole with cardiac pacing. Epilepsia 2011; 52: e16-e19.

21. Duplyakov D, Golovina G, Lyukshina N, Surkova E, Elger CE, Surges R. Syncope, seizure-induced bradycardia and asystole: Two cases and review of clinical and pathophysiological features. Seizure 2014; 23: 506-511. 